
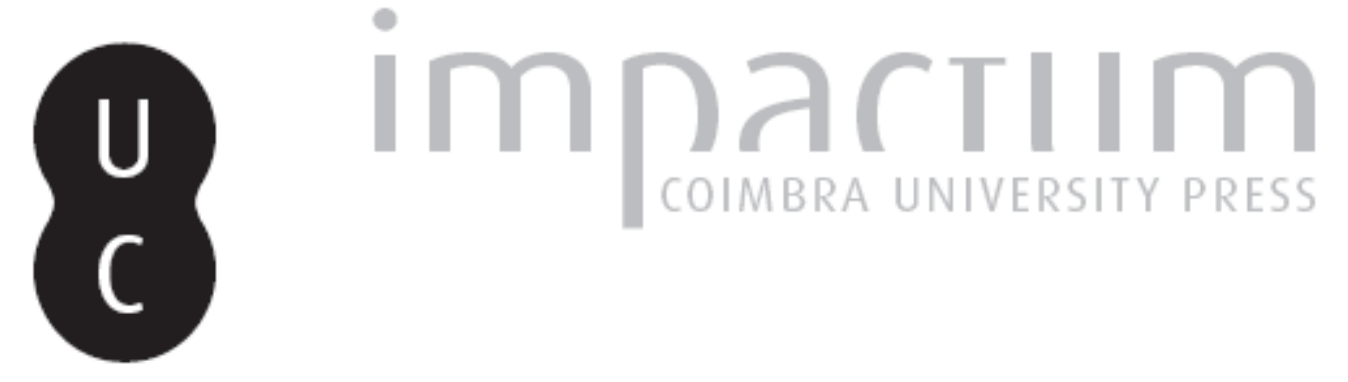

PO.EX: arquivo, subarquivo, meta-arquivo $=[$ Recensão a] Rui Torres \& Sandy
Baldwin, PO.EX: Essays from Portugal on Cyberliterature and Intermedia (By Pedro
Barbosa, Ana Hatherly and E. M. de Melo e Castro)

Autor(es): $\quad$ Marques, Diogo

Publicado por: Centro de Literatura Portuguesa; Imprensa da Universidade de Coimbra

URL

persistente:

URI:http://hdl.handle.net/10316.2/37801

DOI: $\quad$ DOI:http://dx.doi.org/10.14195/2182-8830_3-1_21

Accessed : $\quad$ 26-Apr-2023 14:20:58

A navegação consulta e descarregamento dos títulos inseridos nas Bibliotecas Digitais UC Digitalis, UC Pombalina e UC Impactum, pressupõem a aceitação plena e sem reservas dos Termos e Condições de Uso destas Bibliotecas Digitais, disponíveis em https://digitalis.uc.pt/pt-pt/termos.

Conforme exposto nos referidos Termos e Condições de Uso, o descarregamento de títulos de acesso restrito requer uma licença válida de autorização devendo o utilizador aceder ao(s) documento(s) a partir de um endereço de IP da instituição detentora da supramencionada licença.

Ao utilizador é apenas permitido o descarregamento para uso pessoal, pelo que o emprego do(s) título(s) descarregado(s) para outro fim, designadamente comercial, carece de autorização do respetivo autor ou editor da obra.

Na medida em que todas as obras da UC Digitalis se encontram protegidas pelo Código do Direito de Autor e Direitos Conexos e demais legislação aplicável, toda a cópia, parcial ou total, deste documento, nos casos em que é legalmente admitida, deverá conter ou fazer-se acompanhar por este aviso. 


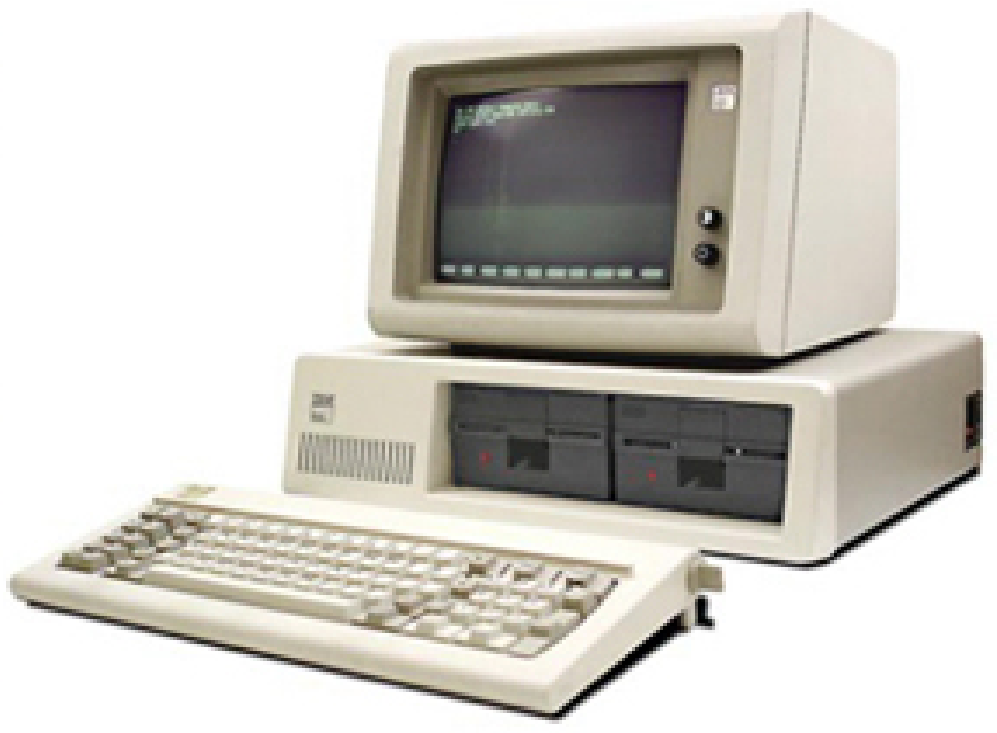

Vol. 3.1 (2015)

ISSN 2182-8830

'Artes, Média e Cultura Digital'

Paulo Silva Pereira e Pedro Serra (orgs.) 


\section{PO.EX: Arquivo, Subarquivo, Meta-Arquivo}

\section{Diogo Marques \\ CLP | Universidade de Coimbra \\ Bolseiro da FCT}

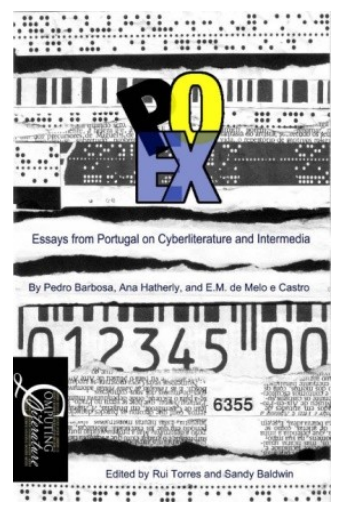

Rui Torres \& Sandy Baldwin, PO.EX: Essays from Portugal on Cyberliterature and Intermedia (By Pedro Barbosa, Ana Hatherly and E. M. de Melo e Castro). Morgantown, WV, Center for Literary Computing, 2014, 282 pp.

ISBN 978-1-938228-74-2

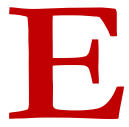

m "Fim de Partida" (Endgame), peça em um acto escrita em 1957 e levada pela primeira vez a público nesse mesmo ano, Samuel Beckett coloca em cena dois pares de personagens confinados a quatro paredes, embora os seus destinos se encontrem já traçados, ainda antes de subir o pano. Não obstante - para nós, leitores e espectadores, como para eles, Hamm e Clov, Nagg e Nell - olhar para este fim de partida como um fim em si mesmo ou, pelo contrário, como representativo de um novo início, não se afigura tarefa fácil. E neste sentido, à semelhança da fita de Möbius, frases como a que Hamm profere no seu monólogo central, "The end is in the beginning and yet you go on", não fazem senão comprovar essa mesma indistinção entre fim e princípio. De modo similar, discussões em torno da literatura electrónica como representativa do fim da literatura, ou até mesmo a ideia de que a literatura electrónica é o início de algo novo, podem ser, de facto, demasiado escatológicas e teleológicas. Contudo, se por um lado é possível encontrar posições teóricas que consideram que cada nova obra literária digital, publicação académica ou arquivo tendem a questionar os paradigmas vigentes, por outro lado, são vários os teorizadores que lhe reconhecem uma proto-história que remonta a meados do século passado (se aceitarmos os "textos estocásticos" de Theo Lutz como experiência fundacional). Ora, tal bipolarização parece estar assente em duas perspectivas antagónicas: uma partindo da ideia de que a literatura electrónica não pode ser 
considerada como representativa de algo novo, e a outra partindo do princípio de que, sendo um campo relativamente recente, muito haverá ainda por ser dito e explorado. PO.EX: Essays from Portugal on Cyberliterature and Intermedia é uma publicação representativa desta mesma condição, apresentando-se, por um lado, com intenções de polemizar perspectivas vigentes sobre a história da literatura electrónica, bem como da criação literária avant-garde em Portugal, e, por outro, procurando questionar e ressituar barras cronológicas que se encontram ainda longe de uma desejável condição de estabilidade.

Constituindo-se como uma recolha de enquadramentos e teorizações que três dos nomes mais "internacionais" do experimentalismo português procuraram fazer no percurso da sua criação artística (Ana Hatherly, E. M. de Melo e Castro, e Pedro Barbosa), e num espectro temporal que vai dos anos 1960 até ao presente, o seu objectivo não parece passar, no entanto, pela proclamação categórica de uma visão alternativa da história da literatura electrónica na sua relação com o Experimentalismo Português. Fazê-lo seria emular as diversas investigações na área que têm procurado estabelecer uma relação directa, não só com a poesia concreta, mas também apontando para a sua contaminação por parte de uma série de práticas artísticas avant-garde. PO.EX não nega, é certo, uma história preexistente, assente em diversas camadas sedimentadas de tecnologias e de diferentes processos de experimentação. Mas é na utilização intermedial que faz destas que se estabelece a diferença, isto é, não olhando para a história da literatura electrónica como uma sequência linear, com princípios e fins pré-estabelecidos, mas partindo da ideia de uma experimentação dos media tecnológicos (analógicos e/ou digitais) enquanto artefactos culturais que, numa relação simbiótica entre homem e media, potenciam a criação literária. Sendo que a própria imagem escolhida para a capa da publicação (a partir de um poema visual da autoria de César Figueiredo) parece atestar essa mesma imagem, de camadas geológicas de media tecnológicos, que se sobrepõem como colagens/montagens com rasgos mais e menos evidentes entre si.

A diferença temporal entre os vários artigos reunidos é igualmente relevante, sobretudo por ser representativa de um diálogo entre instâncias temporais, que é aqui apresentado em diferentes graus. Primeiro, pensando nos três autores que encabeçam a referida obra, não vemos senão três práticas distintas de pensar a criação literária, nomeadamente, embora não de modo exclusivo, a poesia visual, a videopoesia e a poesia combinatória e gerativa. Em segundo lugar, e de modo mais concreto, o facto de todos eles - não só com as suas obras artísticas, mas também por meio dos referidos enquadramentos e teorizações que sempre acompanharam as obras - revisitarem o passado para pensar o presente e o futuro. Hatherly, recuperando o período Barroco e, em certa medida, o Medieval; Melo e Castro, recuando de igual modo ao Barroco e explorando o Modernismo; Barbosa, recombinando a tradição experimentalista com inputs e outputs semelhantes a alguns dos exercícios levados a cabo pelas práticas surrealistas. Curiosamente, todos fazendo 
uso de Camões, contrariando, precisamente, a ideia de que a literatura portuguesa se inicia e se esgota em Os Lusíadas.

E este é, sem dúvida, um primeiro objectivo central desta publicação: contrariar e ressituar, de modo radical e polémico, uma determinada visão de um Portugal imaginário, aqui substituída por uma outra visão gerada por imaginários artísticos. Sendo que o radical e o polémico acabam por surgir aqui como efeitos legítimos de uma contaminação marginal e contracultural que permeia as vanguardas. E perguntamo-nos, como perguntam os seus organizadores no texto que introduz a obra: "porquê Portugal?", um país com um papel aparentemente minoritário no campo da crítica literária contemporânea, para não falar de áreas como os estudos dos novos media e literatura electrónica? É que os ditos imaginários artísticos, que neste livro se apresentam em língua inglesa, completando assim os processos de negociação transatlântica que se iniciaram há décadas (embora com um fluxo muito mais intenso num sentido do que noutro), são, antes de mais, arquivo. Ou melhor, um subarquivo que é simultaneamente um meta-arquivo. Primeiro, subarquivo, no sentido em que apenas representam uma pequena parcela de um imenso trabalho de recuperação das práticas experimentalistas em Portugal: o Arquivo Digital da PO.EX (http://po-ex.net/). Em segundo lugar, metaarquivo, por se constituir como arquivo vivo em contínua reconceptualização, reflectindo e experimentando sobre si próprio. O que nos leva ao segundo objectivo principal da obra: contrariar uma dada hegemonia do hipertexto associado, não raras vezes, às bases fundacionais da literatura electrónica. Por outras palavras, recuperar preocupações que, embora relativamente distantes no tempo, se apresentam ainda como "inovadoras". Mais ainda, questionando perspectivas arqueológicas dos media, que tendem a fazer coincidir literatura electrónica com o que é próprio da máquina, desconsiderando assim os processos analógicos de criação literária, ou que antecedem a processualidade electrónica. Trata-se aqui, portanto, de uma série sucessiva de processos de perda e de recuperação, num circuito contínuo composto de acções e retroacções. Neste caso concreto, uma recuperação em duas frentes: pelo impresso e pelo digital (de referir o acesso livre a todos os textos a partir da página Web do Arquivo PO.EX). Textos “perdidos", e agora recuperados, que permitem pensar as práticas poéticas digitais com base numa reinvenção constante da criação literária.

Mas o diálogo entre passado, presente e futuro que se encontra expresso na própria estrutura da obra, com dois prelúdios, seguidos de duas partes dedicadas à Visualidade e Intermedialidade na Literatura Experimental e à Combinação e Geratividade na Ciberliteratura, não se esgota nos três autores referidos anteriormente. Também os três ensaios finais são representativos de uma continuação do legado experimentalista que não encontra limites temporais a montante ou a jusante. Não escondendo a devida reverência ao trio apresentado na capa, os três ensaios que encerram esta publicação trazem para a discussão outros textos, outros autores, outros arquivos e outros 
modos de entender a criação literária. Rui Torres demonstra, por meio de uma conexão "plagiotrópica", como três momentos de criação literária com mais de um século de distância temporal continuam a comunicar entre si, renovando-se constantemente a cada nova leitura. Pedro Reis reafirma a ideia de que a obra literária digital permite entender e analisar técnicas de composição utilizadas pelas práticas experimentalistas. Por último, Manuel Portela, aponta para o facto de o Arquivo Digital da PO.EX ser muito mais do que um mero repositório, e salienta ainda a pertinência dos exercícios de "remediação" digital que este mesmo inovador arquivo apresenta. Exercícios que recuperam momentos específicos de criação literária portuguesa, permitindo, também eles, uma reflexão sobre uma continuidade histórica que não é feita, aparentemente, de compartimentos estanques.

Inserida na colecção "Computing Literature", série de textos publicada em parceria com o Center for Literary Computing da West Virginia e com o Laboratoire Paragraphe da Université Paris 8 (e que se assume como única colecção de monografias inteiramente dedicadas ao tema), PO.EX: Essays from Portugal on Cyberliterature and Intermedia será, porventura, a constatação de que, e recuperando Manuel António Pina, talvez seja "apenas um pouco tarde" para reflectir sobre o princípio e o fim da literatura electrónica. Claro que, face a uma tal intermedialidade e interdisciplinaridade, tais práticas artísticas e ensaios que delas derivam não se resumem à criação literária, pelo que poderíamos sempre relançar outra pergunta, tão recorrente quanto polémica: "mas, afinal de contas, isto também é literatura?". A esta, nem os organizadores de PO.EX, nem os autores por estes recuperados quereriam, por certo, responder. Mas talvez o repto final deixado por Rui Torres e Sandy Baldwin no texto introdutório, "take this as a handbook and begin experimenting poetically", possa, de algum modo, permitir que se termine o jogo para iniciar outro. Por exemplo, por via plagiotrópica, e especificamente pela "recombinação", lá está, de uma frase "perdida" de Peter Roehr, recuperada em tempos por Alberto Pimenta, e que agora aqui se faz arquivar: "Se o que experiencio é literatura, não sei. Por outro lado, não sei que outra coisa poderia ser”. 